\title{
Systematic Investigation of Alkyl Sulfonate Initiators for the Cationic Ring- Opening Polymerization of 2-Oxazolines revealing Optimal Combinations of Monomers and Initiators
}

\author{
Mathias Glassner, ${ }^{\dagger}$ Dagmar R. D’hooge,${ }^{\dagger}$ Jin Young Park, ${ }^{\dagger}$ Paul H. M. Van Steenberge, ${ }^{\star}$ Bryn D. \\ Monnery, ${ }^{\dagger}$ Marie-Françoise Reyniers, ${ }^{\ddagger}$ and Richard Hoogenboom ${ }^{\dagger} *$ \\ Corresponding Author \\ *E-mail: richard.hoogenboom@ugent.be \\ †Supramolecular Chemistry Group, Department of Organic and Macromolecular Chemistry, Ghent University, \\ Krijgslaan 281-S4, 9000 Ghent, Belgium \\ Laboratory for Chemical Technology, Ghent University, Technologiepark 914, 9052 Zwijnaarde (Ghent), Belgium
}

\begin{abstract}
A systematic kinetic investigation of the living cationic ring-opening polymerization (CROP) involving 2ethyl-2-oxazoline, 2-methyl-2-oxazoline, and 2-phenyl-2-oxazoline employing a series of alkyl sulfonate initiators with variation of the alkyl initiating fragment (methyl, ethyl, iso-propyl) and the leaving group/counterion (tosylate, nosylate, triflate) is reported. The study reveals that the initiation and propagation reactivity increases in the order tosylate $<$ nosylate $<$ triflate. Slow initiation is observed for EtOTs, while EtONs is a sufficiently fast initiator even for 2-phenyl-2-oxazoline. It is thus recommended to avoid the use of alkyl tosylates, except MeOTs, as initiators for the CROP of 2-alkyl-2-oxazolines. Although triflates are generally the best initiators, the use of the more stable and easier synthesizable nosylates provides a suitable alternative for the design of functional initiators for the CROP of 2-alkyl-2oxazolines.
\end{abstract}

\section{Introduction}

The living cationic ring-opening polymerization (CROP) of 2-substituted-2-oxazolines was first described in the mid1960s by four independent research groups[1-4]. The resulting poly(2-oxazoline)s, which can be regarded as pseudo-polypeptides, have received considerable attention in recent years for biomedical applications[1,2] and as thermoresponsive materials[3]. Telechelic poly(2-oxazoline)s can be synthesized utilizing functional initiators or terminating agents[4]. As illustrated in Scheme 1, the CROP of 2oxazolines, selecting 2-ethyl-2-oxazoline as represeantative monomer, is initiated by an electrophile that reacts with the endocyclic nitrogen atom of the oxazoline ring to form an oxazolinium cation. Propagation occurs via nucleophilic attack of the monomer on the oxazolinium species, resulting in ring-opening and the formation of an amide by isomerization. Typical initiators are alkyl or benzyl halides including 
chlorides,[5] bromides[5] and iodides[6] or alkyl sulfonates such as $p$-toluenesulfonates (tosylates),[7] $p$-nitrobenzenesulfonates (nosylates)[8] and trifluoromethanesulfonates (triflates)[9].

To obtain well-defined polymers with narrow molar mass distributions and to gain good control over the polymerization, initiation should be quantitative and fast with respect to propagation (initiation rate coefficient, $k_{\mathrm{i}} \gg$ propagation rate coefficient, $k_{\mathrm{p}}$ ). These requirements can be fulfilled using a simple electrophilic initiator such as methyl tosylate. When employing a functional initiator, which opens the path to more complex macromolecular architectures, however, this task becomes more challenging. For example, slow initiation has been reported for dodecyl and oleyl tosylate, $[10,11] 2-(p-$ toluenesulfonato)ethyl methacrylate[12] as well as tosylated poly(dimethylsiloxane-comethylhydrosiloxane) macro-initiators[13]. This issue of slow initiation could be partially resolved by the use of the respective nosylates[11, 12] or triflates[10, 14]. The importance of careful selection of the alkyl group was clearly demonstrated by the comparison of butynyl and propargyl tosylate where only the latter one exhibited a sufficiently fast initiation[15]. Despite the aforementioned experimental studies there is still a lack of a systematic investigation of initiators for the CROP of 2-oxazolines with variation of both the alkyl group and the sulfonate leaving group, acting as counterion during the polymerization. Nonetheless, based on three independent reports on using sulfonate esters of pentaerythritol for the preparation of star-shaped poly(2-oxazolines)[16-18] it may be suggested that nosylates and triflates are better initiators than tosylates.

Initiation

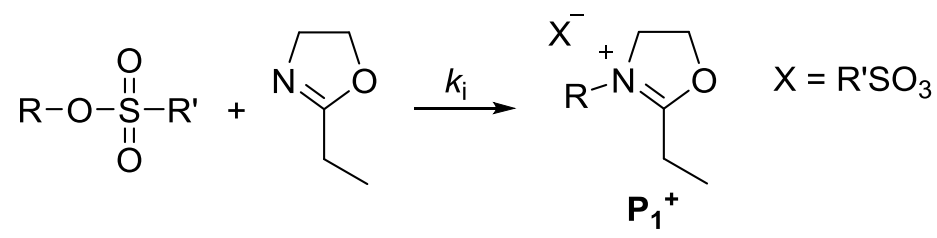

Propagation
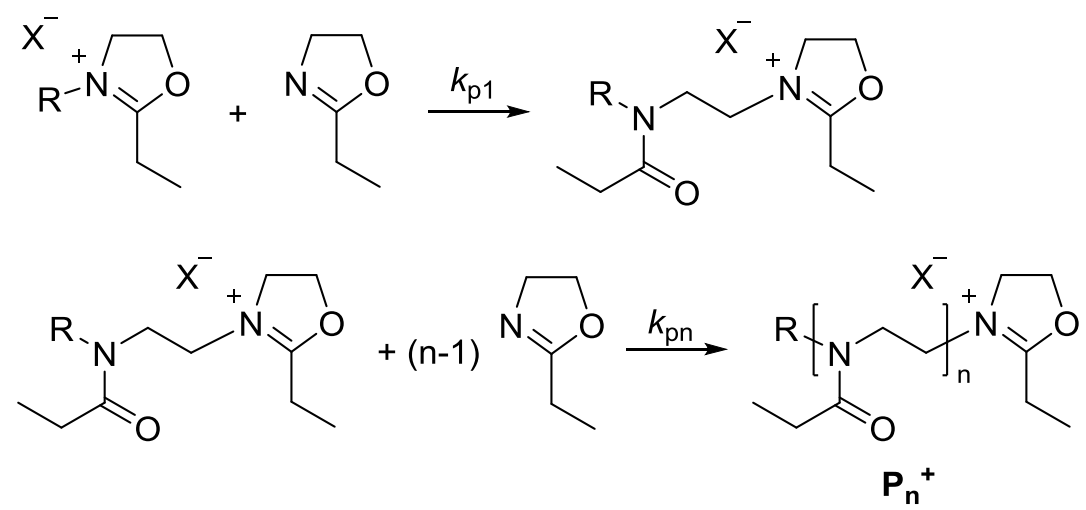

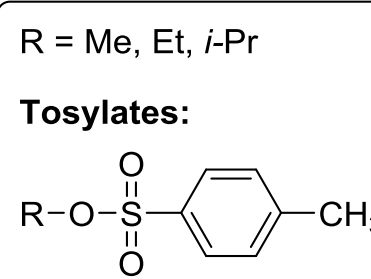

Nosylates:

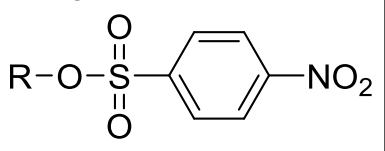

Triflates:

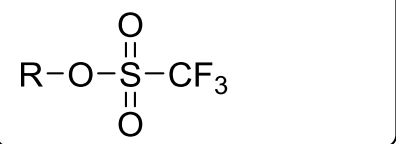

Scheme 1 Left: Schematic representation of the mechanism of the CROP of -2-oxazolines initiated by alkyl sulfonates; 2-ethyl-2-oxazoline is selected as representative monomer. The chemical structures of the investigated initiators are shown on the right. 
In this work, a systematic kinetic investigation of the CROP of 2-ethyl-2-oxazoline (EtOx), 2-methyl-2oxazoline (MeOx) and 2-phenyl-2-oxazoline ( $\mathrm{PhOx}$ ) is presented employing a series of alkyl sulfonate initiators with variation of the alkyl initiating fragment (methyl, ethyl, iso-propyl) and the leaving group/counterion (tosylate, nosylate, triflate). Alkyl sulfonates are chosen because it was previously shown that with such initiators the CROP proceeds exclusively via the cationic species shown in Scheme 1. A mixture of covalent and ionic species is thus avoided and, therefore, we favor these initiators over halide initiators that often lead to combined cationic and covalent propagating species[5, 19]. The propagation rate coefficients are calculated from the linear first-order kinetic plots in case of fast initiation while possible slow initiators are identified based on non-linear first order kinetic plots for which regression analysis was used to determine initiation and propagation rate coefficients.

\section{Experimental Section}

Materials and Instrumentation Acetonitrile (Aldrich) was dried in a solvent purification system (J. C. Meyer) before use as a polymerization solvent. 2-ethyl-2-oxazoline (EtOx), 2-methyl-2-oxazoline (MeOx) and 2-phenyl-2-oxazoline (PhOx, Aldrich) were distilled over barium oxide and stored under argon. Methyl tosylate, ethyl tosylate, methyl triflate and ethyl triflate (Aldrich) were distilled and stored under argon. Methyl nosylate,[20] ethyl nosylate,[21] and iso-propyl nosylate[22] were synthesized according to literature procedures, recrystallized twice from ethanol, dried under high vacuum and stored under argon. All other chemicals were used as received.

All polymerizations were performed in capped vials in a microwave reactor (Biotage) equipped with an infrared (IR) temperature sensor.

Gas chromatography (GC) was performed on a 7890A from Agilent Technologies with an Agilent J\&W Advanced Capillary GC column $(30 \mathrm{~m}, 0.320 \mathrm{~mm}$, and $0.25 \mu \mathrm{m})$. Injections were performed with an Agilent Technologies 7693 auto sampler.

Size exclusion chromatography (SEC) measurements were performed on an Agilent 1260-series equipped with a 1260 ISO-pump, a 1260 Diode Array Detector (DAD), a 1260 Refractive Index Detector (RID), and a PSS Gram30 column in series with a PSS Gram1000 column inside a 1260 Thermostated Column Compartment (TCC) at $50^{\circ} \mathrm{C}$ using dimethylacetamide containing $50 \mathrm{mM}$ of $\mathrm{LiCl}$ (flow rate of $0.59 \mathrm{~mL}$ $\mathrm{min}^{-1}$ ) as solvent. Molar masses were measured against poly(methyl methacrylate) standards.

Matrix assisted laser desorption/ionization time of flight mass spectrometry (MALDI-TOF MS) was performed on an Applied Biosystems Voyager De STR MALDI-TOF mass spectrometer equipped with 2 $\mathrm{m}$ linear and $3 \mathrm{~m}$ reflector flight tubes. All mass spectra were obtained with an accelerating potential of 20 $\mathrm{kV}$ in positive ion mode and in reflectron mode (matrix: trans-2-[3-(4-tert-butylphenyl)-2-methyl-2propenylidene]malononitrile (DCTB); salt: sodium trifluoroacetate). 
Kinetic Investigations of Microwave-Assisted Polymerizations. Kinetic investigations of the polymerizations were performed under microwave irradiation at $80^{\circ} \mathrm{C}$ with an initial monomer concentration of $4 \mathrm{M}$ in acetonitrile and an initial molar ratio of monomer to initiator $\left([\mathrm{M}]_{0}:[\mathrm{I}]_{0}\right)$ equal to 50:1. A stock solution of the polymerization mixture was prepared in a glove-box (Vigor Gas Purification Technologies) and divided into individual vials, which were crimped air-tight inside the glove-box before transfer to the microwave reactor. After microwave irradiation the polymerization mixtures were cooled to ambient temperature and samples were taken for GC and SEC analysis. For each initiator the kinetic investigation was carried out three times, indicative of an intensive experimental study. For MALDI-TOF MS analysis, polymerizations were quenched by addition of water and samples of the reaction mixture were analyzed without further purification.

\section{Results and Discussion}

Kinetic investigation of the CROP of 2-ethyl-2-oxazoline (EtOx)

As indicated in previous work, very fast CROPs of various 2-oxazolines, including EtOx, can be achieved by microwave assisted polymerization in acetonitrile at a relatively high temperature of $140^{\circ} \mathrm{C}[23,24]$. In the present contribution, the CROP of EtOx with various alkyl sulfonate initiators is investigated using the previously optimized conditions, yet at a lower temperature of $80^{\circ} \mathrm{C}$. This transition is made, as a lower temperature is often more suitable for initiators bearing thermally less stable functional groups and slow initiation becomes more clearly visible when the polymerization is conducted at such temperatures. Based on the reaction mechanism shown in Scheme 1, the monomer and initiator disappearance rate are respectively given by:

$$
\begin{aligned}
& -\frac{d[\mathrm{M}]}{d t}=k_{i}[\mathrm{I}][\mathrm{M}]+k_{p 1}\left[\mathrm{P}_{1}^{+}\right][\mathrm{M}]+k_{p n}[\mathrm{M}] \sum_{n=2}\left[\mathrm{P}_{\mathrm{n}}^{+}\right] \\
& -\frac{d[\mathrm{I}]}{d t}=k_{i}[\mathrm{I}][\mathrm{M}]
\end{aligned}
$$

where $[\mathrm{I}]$ and $[\mathrm{M}]$ are the concentration of initiator and monomer at a time $t$. Under the assumption that $k_{\mathrm{p} 1}$ equals $k_{\mathrm{pn}}$ Equation (1) can be simplified into [7]:

$-\frac{d[\mathrm{M}]}{d t}=k_{i}[\mathrm{I}][\mathrm{M}]+k_{p}\left[\mathrm{P}^{+}\right][\mathrm{M}]$

with $k_{p 1}=k_{p n}=k_{p}$ and $\left[\mathrm{P}^{+}\right]=\sum_{\mathrm{n}=1}\left[\mathrm{P}_{\mathrm{n}}^{+}\right]$. For a fast $\left(k_{\mathrm{i}}>k_{\mathrm{p}}\right)$ and quantitative initiation, the concentration of the living macrospecies $\left[\mathrm{P}^{+}\right]$can be replaced by the initial initiator concentration $[\mathrm{I}]_{0}$ and integration of equation (3) gives following simple analytical expression:

$\ln \frac{[\mathrm{M}]_{0}}{[\mathrm{M}]_{t}}=k_{p} \cdot[\mathrm{I}]_{0} \cdot t$ 
Hence, for (quasi-)instantaneous initiation, the polymerization can be assumed to be first-order with respect to monomer and it suffices to determine a single kinetic parameter, i.e. $k_{\mathrm{p}}$, to describe the conversion profile. On the other hand in case the initiation step cannot be kinetically ignored, the conversion profile has to be described by Equations (2) and (3), requiring therefore two kinetic parameters, i.e. $k_{\mathrm{i}}$ and $k_{\mathrm{p}}$.

For the methyl based initiators, the measured $\ln \left([\mathrm{M}]_{0} /[\mathrm{M}]_{\mathrm{t}}\right)$ versus reaction time plots using $[\mathrm{M}]_{0}:[\mathrm{I}]_{0}=$ $50: 1$ and $[\mathrm{M}]_{0}=4 \mathrm{M}$ for the polymerization of EtOx in acetonitrile at $80^{\circ} \mathrm{C}$ are shown in Figure 1 . Only small differences are observed for the polymerizations with methyl tosylate (MeOTs), methyl nosylate (MeONs) and methyl triflate (MeOTf) as initiator. First-order kinetics as evidenced by the linear increase of $\ln \left([\mathrm{M}]_{0} /[\mathrm{M}]_{\mathrm{t}}\right)$ with time are observed for all three initiators, implying fast and efficient initiations. Calculation of the propagation rate coefficients from the slopes of the linear fits (Table 1) reveals that $k_{\mathrm{p}}$ increases in the order MeOTs $<$ MeONs < MeOTf which is in line with the decreasing nucleophilicity/increasing nucleofugicity of the counterions. Moreover, the linear increases of the number average molar mass $\left(M_{\mathrm{n}}\right)$ with conversion (Figure 1 bottom) in combination with narrow molar mass distributions $(\nexists<1.15)$ further demonstrate that the polymerizations proceed in a controlled/living manner for all three initiators with methyl as the alkylating group.
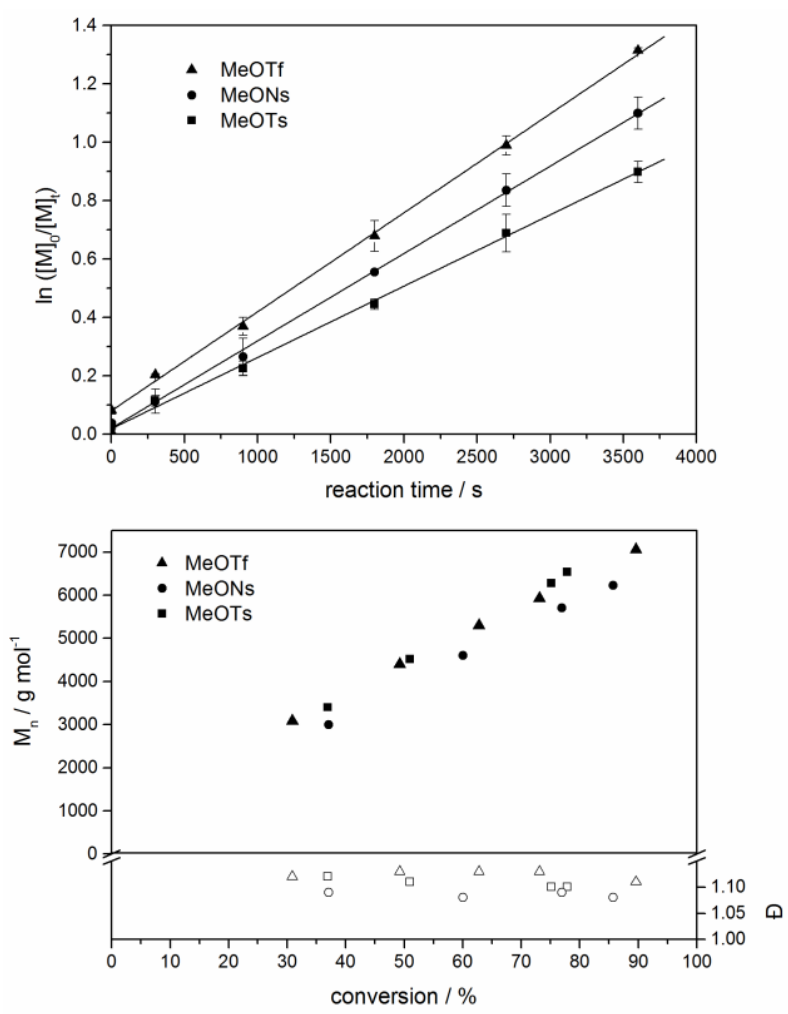

Figure 1. Kinetic plots for the CROP of EtOx (4M) in acetonitrile initiated by MeOTs, MeONs and MeOTf at $80^{\circ} \mathrm{C}$ in acetonitrile (top). The lines represent linear fits (Equation (4): fast initiation). Corresponding number average molar mass $\left(M_{\mathrm{n}}\right)$ against conversion plot, including the dispersities $(\nexists)$ (bottom); corresponding estimates are listed in Table 1. 
Table 1 Propagation rate coefficients at $80^{\circ} \mathrm{C}$ calculated from the slopes of the linear fits of the CROP of EtOx (4M) in acetonitrile initiated by MeOTs, MeONs, MeOTf, EtONs, and EtOTf (Equation (4)) and the number average molar masses $\left(M_{\mathrm{n}}\right)$ and dispersities $(\nexists)$ of the samples at complete conversion, including as well the EtOTs case.

\begin{tabular}{llll}
\hline Initiator & $k_{\mathrm{p}} / 10^{-3} \mathrm{~L} \mathrm{~mol}^{-1} \mathrm{~s}^{-1}$ & $M_{\mathrm{n}}{ }^{\mathrm{a}} / \mathrm{g} \mathrm{mol}^{-1} \bigoplus^{\mathrm{a}}$ \\
\hline MeOTs & $3.39 \pm 0.17$ & 6500 & 1.10 \\
MeONs & $4.13 \pm 0.25$ & 6200 & 1.08 \\
MeOTf & $4.35 \pm 0.02$ & 7100 & 1.11 \\
EtOTs & not determined & 9000 & 1.22 \\
EtONs & $4.13 \pm 0.10$ & 7000 & 1.09 \\
EtOTf & $4.35 \pm 0.13$ & 6800 & 1.08 \\
\hline
\end{tabular}

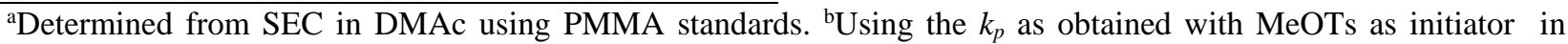
combination with Equation (2) and (3) $k_{i}$ is estimated as $(9.93 \pm 3.92) 10^{-5} \mathrm{~L} \mathrm{~mol}^{-1} \mathrm{~s}^{-1}$, confirming the slow initiation and the failing of Equation (4). 
To investigate the effect of the alkyl group on the initiation reaction, the methyl groups of the preceding series of initiators were subsequently replaced by ethyl groups, which decreases the electrophilicity of the initiators. Kinetic studies with EtOTs, EtONs and EtOTf as initiators were performed under identical conditions as for the methyl initiators $\left(80^{\circ} \mathrm{C} ;[\mathrm{M}]_{0}:[\mathrm{I}]_{0}=50: 1 ;[\mathrm{M}]_{0}=4 \mathrm{M}\right)$. The kinetic plots of $\ln \left([\mathrm{M}]_{0} /[\mathrm{M}]_{\mathrm{t}}\right)$ against time as depicted in Figure 2 only reveal a linear increase for the polymerizations initiated by EtONs and EtOTf. The propagation rate coefficients calculated from the slopes of the linear fits (Table 1) are in perfect agreement with those obtained from the respective methyl initiators, which is to be expected as the propagation reactivity is only governed by the counterion and is not affected by the alkyl group, which is located on the opposite end of the polymer chain, i.e. far away from the reactive center (Scheme 1).
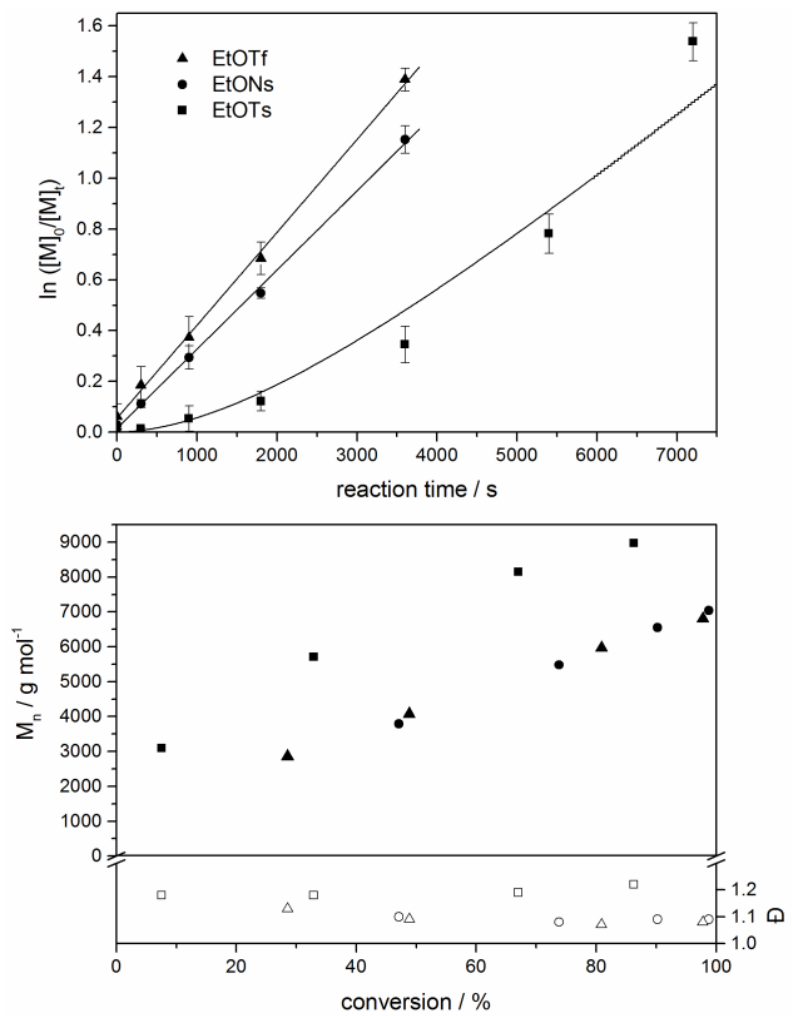

Figure 2 Kinetic plots for the CROP of EtOx (4M) initiated by EtOTs, EtONs and EtOTf at $80^{\circ} \mathrm{C}$ in acetonitrile (top). The lines for EtOTf and EtONs represent linear fits (Equation (4); fast initiation). The line for EtOTs is obtained by regression analysis with Equation (2) and (3). Corresponding number average molar mass $\left(M_{\mathrm{n}}\right)$ against conversion plot, including the dispersity $(\bigoplus)$ (bottom). Corresponding estimates are listed in Table 1.

In contrast to EtONs and EtOTf, the polymerization initiated with EtOTs does not follow first-order kinetics. Inspection of the plot in Figure 2 shows a non-linear increase of the conversion with time. The observed change of $\ln \left([\mathrm{M}]_{0} /[\mathrm{M}]_{\mathrm{t}}\right)$ with time can be explained by a relatively slow initiation reaction resulting in a slow build-up of the concentration of propagating species. This is also confirmed by regression analysis based on Equation (2) and (3), using the $k_{p}$ value as determined in Table 1 for the 
corresponding methyl initiator leading to the same counterion (MeOTs; $k_{p}=3.39 \times 10^{-3} \mathrm{~L} \mathrm{~mol}^{-1} \mathrm{~s}^{-1}$ ). For this regression analysis the Levenberg-Marquardt algorithm is selected[25-27]. Parameter estimation leads to a value of $9.93 \times 10^{-5} \mathrm{~L} \mathrm{~mol}^{-1} \mathrm{~s}^{-1}$ for $k_{i}$, which is significantly lower than the $k_{p}$ value, reflecting the observed non-linear increase of $\ln \left([\mathrm{M}]_{0} /[\mathrm{M}]_{\mathrm{t}}\right)$ versus time in Figure 2.

The slow initiation with EtOTs is also confirmed by the $M_{\mathrm{n}}$ and dispersity against conversion plots (Figure 2 bottom) that reveal a steeper increase of $M_{\mathrm{n}}$ for low conversions compared to the EtONs and EtOTf initiated polymerizations and larger dispersities. The final size exclusion chromatography (SEC) traces shown in Figure 3 also reflect the differences of the initiation rates. Whereas the SEC traces of the EtONs and EtOTf initiated polymers are nearly identical and narrow, the polymer obtained from initiation with EtOTs exhibits a higher molar mass and a strong tailing towards longer retention times (lower molar mass) underpinning the variable concentration of propagating species throughout a significant part of the polymerization.

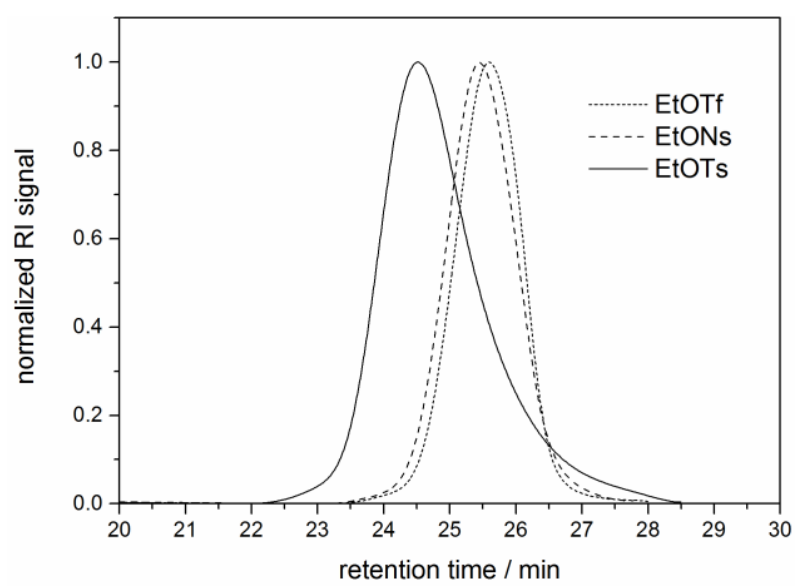

Figure 3 SEC traces of poly(2-ethyl-2-oxazoline)s prepared by initiation with EtOTs, EtONs and EtOTf obtained at complete monomer conversion (conditions: see caption Figure 2).

The previous observations, thus, indicate that the use of alkyl tosylates other than MeOTs as initiators for the CROP of 2-ethyl-2-oxazoline should be avoided. On the other hand, nosylates and triflates, having a 10 and $10^{4}$ times higher leaving group ability than tosylates, respectively,[28] are better alternatives. The highest propagation reactivity of triflates makes them at first sight the most promising type of initiators with regard to fast initiation. However, their very high reactivity can make the synthesis of functional triflates challenging and leads to limited stability, even during storage under inert conditions. Furthermore, triflates are generally liquids at ambient temperature while nosylates are crystalline which leads to a higher stability of nosylates and enables their easy purification by recrystallization.

The aforementioned advantages of nosylates motivated us to investigate as well the limitations of the more stable nosylates as initiators for the CROP of 2-alkyl-2-oxazolines. For that purpose iso-propyl nosylate ( $i$ PrONs) bearing a secondary alkyl group was investigated, applying the same conditions as above $\left(80^{\circ} \mathrm{C}\right.$; $\left.[\mathrm{M}]_{0}:[\mathrm{I}]_{0}=50: 1 ;[\mathrm{M}]_{0}=4 \mathrm{M}\right)$. Unfortunately, the corresponding first-order kinetic plot in Figure 4 reveals a 
non-linear increase of $\ln \left([\mathrm{M}]_{0} /[\mathrm{M}]_{\mathrm{t}}\right)$ with time, similar to what was observed for EtOTs, indicating slow initiation. Again regression analysis using the $k_{p}$ value as obtained with the corresponding methyl initiator $\left(k_{p}=4.1310^{-3} \mathrm{~L} \mathrm{~mol}^{-1} \mathrm{~s}^{-1}\right)$ reveals a much lower $k_{i}$ value $\left(k_{i}=1.9910^{-4} \mathrm{~L} \mathrm{~mol}^{-1} \mathrm{~s}^{-1}\right)$ compared to $k_{\mathrm{p}}$. It should be noted that for secondary alkyl groups, triflates might appeal as an alternative, however, the use of iso-propyl triflate as initiator could not be investigated because it rapidly decomposes at room temperature[29].
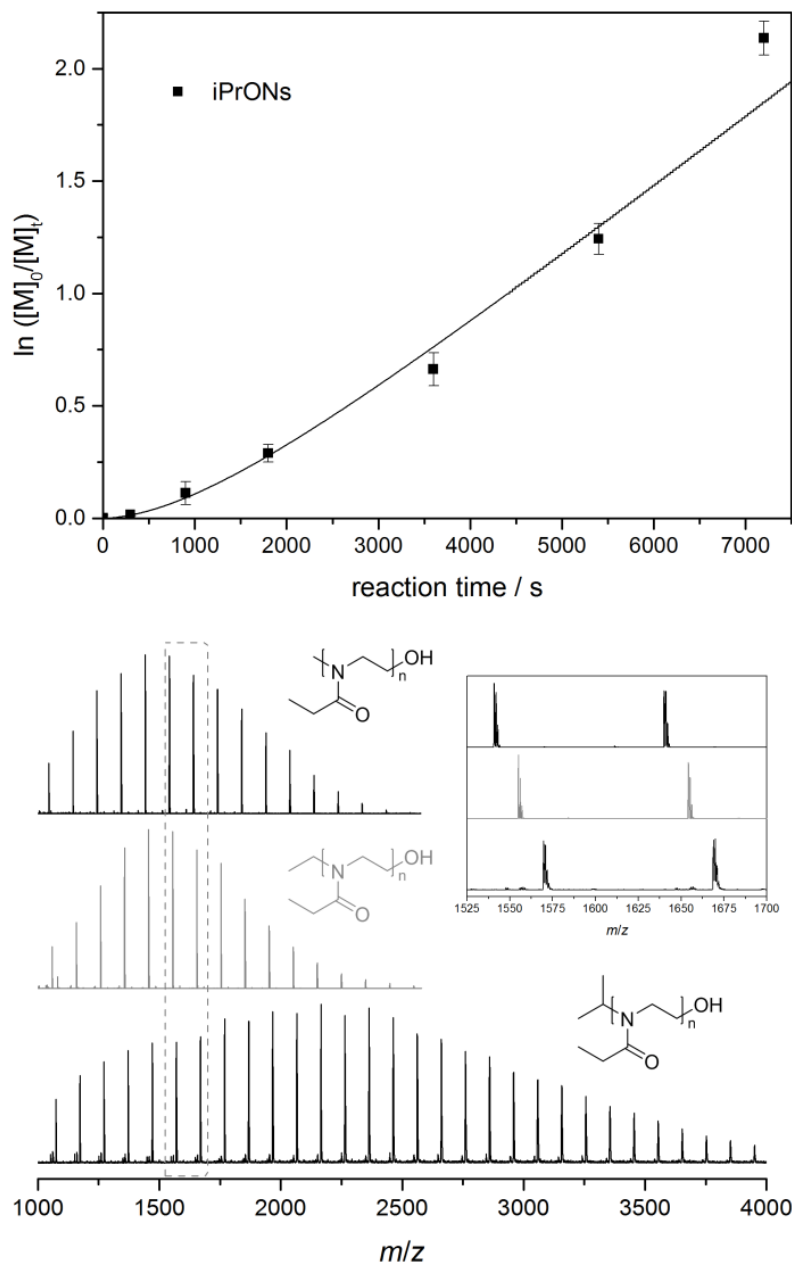

Figure 4 Kinetic plot for the polymerization of EtOx (4M) initiated by $i \operatorname{PrONs}$ at $80^{\circ} \mathrm{C}$ in acetonitrile (top); using the $k_{p}$ as obtained with MeOTs as initiator in Table 1 and Equation (2) and (3), $k_{i}$ is estimated to be $(1,99 \pm 0,51) 10^{-4} \mathrm{~L} \mathrm{~mol}^{-1} \mathrm{~s}^{-1}$, confirming the slow initiation and the failing of Equation (4). MALDITOF mass spectra of poly(2-ethyl-oxazoline)s (bottom) using MeONs (top), EtONs (middle) and $i$ PrONs (bottom) as initiators. The main distributions can be assigned to the sodium adducts $[\mathrm{M}+\mathrm{Na}]^{+}$of the depicted structures. The inset shows an expanded view of the highlighted $\mathrm{m} / \mathrm{z}$ region.

In addition, to ensure that the polymers indeed carry the alkyl group of the nosylate initiators, intermediate samples of the polymerizations initiated by the three different selected nosylates were quenched by addition of water and analyzed by MALDI-TOF MS (Figure 4 bottom). For all three polymers one major distribution is observed that bears the respective alkyl group as initiating fragment. In addition, the mass 
spectrum of the PEtOx initiated by $i$ PrONs exhibits a much broader distribution compared to the MeONs and EtONs initiated polymers, which further demonstrates the slow initiation reaction with $i$ PrONs.

Influence of monomer structure: CROP of 2-methyl-2-oxazoline (MeOx) and 2-phenyl-2-oxazoline (PhOx)

To investigate the influence of the substituent in 2-position of the monomer, polymerization kinetics were also investigated with a more nucleophilic/reactive monomer, namely 2-methyl-2-oxazoline (MeOx), as well as with 2-phenyl-2-oxazoline (PhOx), which can be seen as an example for a less nucleophilic/reactive monomer. For these additional experiments only the initiators with ethyl as the alkylating group were selected because they exhibit the most important difference in the CROP of EtOx. In particular, it is important to investigate if EtOTs which revealed a relatively slow initiation reaction with EtOx reacts sufficiently fast with the more nucleophilic monomer MeOx.

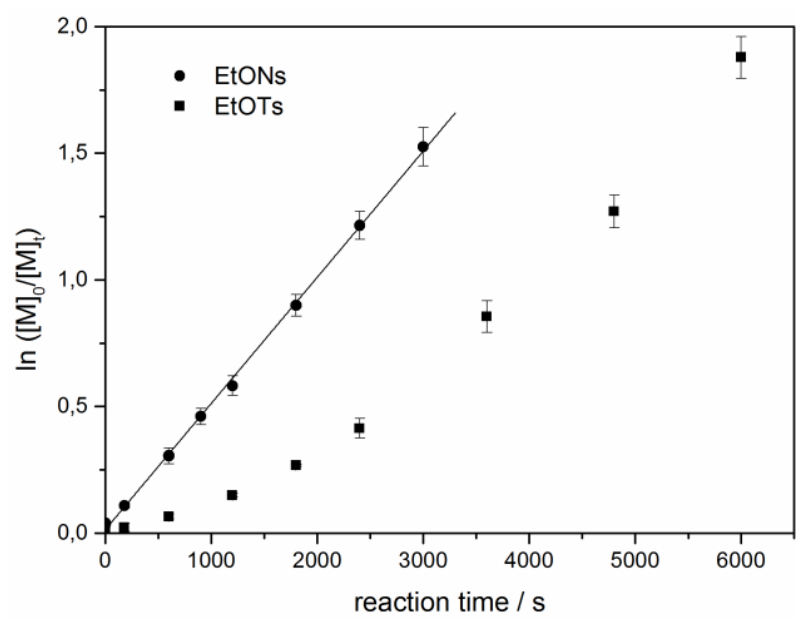

Figure 5 Kinetic plots for the CROP of MeOx initiated by EtOTs and EtONs at $80^{\circ} \mathrm{C}$ in acetonitrile $\left([\mathrm{M}]_{0}:[\mathrm{I}]_{0}=50: 1 ;[\mathrm{M}]_{0}=4 \mathrm{M}\right)$.

The kinetic plots for the CROP of MeOx initiated by EtOTs and EtONs employing the same conditions as for EtOx $\left(80^{\circ} \mathrm{C} ;[\mathrm{M}]_{0}:[\mathrm{I}]_{0}=50: 1 ;[\mathrm{M}]_{0}=4 \mathrm{M}\right)$ are depicted in Figure 5. Inspection of Figure 5 reveals a linear increase of $\ln \left([\mathrm{M}]_{0} /[\mathrm{M}]_{\mathrm{t}}\right)$ with time when EtONs is selected as initiator. Calculation of the propagation rate coefficient from the linear fit gives $k_{\mathrm{p}}=(6.02 \pm 0.31) \times 10^{-3} \mathrm{~L} \mathrm{~mol}^{-1} \mathrm{~s}^{-1}$. In contrast, the polymerization of $\mathrm{MeOx}$ initiated with EtOTs does not follow first-order kinetics and shows a non-linear increase of conversion with time again indicating a non-constant concentration of propagating species that is caused by a relatively slow initiation reaction, albeit this slow initiation is less pronounced compared to EtOx. Regression analysis was not performed in this case because $k_{\mathrm{p}}$ and $k_{i} \mathrm{f}$ are both unknown and only a limited set of data were available to obtain the simultaneous estimation of both rate coefficients 
For the CROP of PhOx, the resulting kinetic plots are given in Figure 6. It has been previously reported that PhOx undergoes a relatively slow initiation reaction with MeOTs[30], so that it is clear that the even less reactive EtOTs is not a suitable initiator for this monomer. To test if EtONs and EtOTf are sufficiently fast initiators for less reactive monomers, the CROP of PhOx which has a lower nucleophilic reactivity than $\mathrm{MeOx}$ and EtOx were thus investigated instead. The kinetic plots reveal a linear increase of $\ln \left([\mathrm{M}]_{0} /[\mathrm{M}]_{\mathrm{t}}\right)$ with time for both initiators demonstrating a fast initiation reaction. So despite the lower nucleophilicity of the monomer, these results demonstrate that alkylation is quite efficient. This is also evident from the high monomer conversion directly after the start of the polymerization ( $c a$. 1 second), which results from initiation and monomer conversion during the heating of the reaction mixture to the polymerization temperature of $80^{\circ} \mathrm{C}$. The propagation rate coefficients $\left(k_{\mathrm{p}}\right)$ calculated from the linear fits are $(0.97 \pm 0.04) \times 10^{-3} \mathrm{~L} \mathrm{~mol}^{-1} \mathrm{~s}^{-1}$ and $(1.06 \pm 0.05) \times 10^{-3} \mathrm{~L} \mathrm{~mol}^{-1} \mathrm{~s}^{-1}$, respectively for EtONs and for EtOTf.

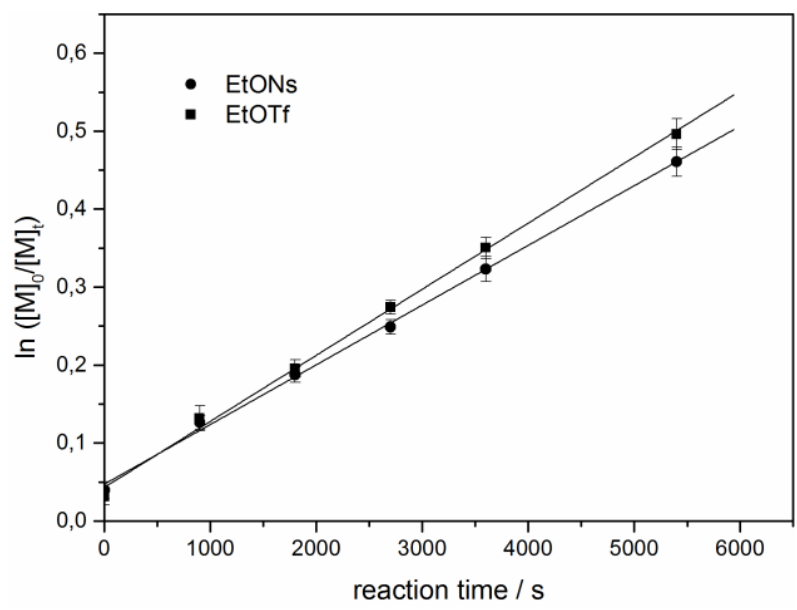

Figure 6 Kinetic plots for the CROP of PhOx initiated by EtONs and EtOTf at $80^{\circ} \mathrm{C}$ in acetonitrile $\left([\mathrm{M}]_{0}:[\mathrm{I}]_{0}=50: 1 ;[\mathrm{M}]_{0}=4 \mathrm{M}\right)$; initial deviation is due to monomer conversion during heating to $80{ }^{\circ} \mathrm{C}$.

\section{Conclusions}

A systematic kinetic study of the CROP of EtOx, MeOx and $\mathrm{PhOx}$ at $80^{\circ} \mathrm{C}$ in acetonitrile with different initiators with varying alkyl and leaving group/counterion revealed that the propagation reactivity increases in the order OTs $<$ ONs $<$ OTf. More important, the initiation reactivity increases in the same order and it is found that EtONs is a sufficiently fast initiator even for PhOx, while EtOTs shows slow initiation, resulting in less control over the polymerization. We thus recommend avoiding the use of alkyl tosylates, except MeOTs, as initiators for the CROP of 2-alkyl-2-oxazolines. Generally, triflates are the 
best initiators. However, the more stable and usually crystalline nosylates should be considered as a suitable alternative as the synthesis, purification and stability of triflates is often problematic, although examples of functional triflate initiators have been reported. In addition, slow initiation was observed with $i$ PrONs, demonstrating the limitations of nosylate initiators with secondary alkyl initiating fragments.

\section{Acknowledgements}

M.G. thanks the Research Foundation - Flanders (FWO) for financial support via a Pegasus Marie Curie Fellowship. D.R.D. acknowledges the FWO for a postdoctoral fellowship. RH is grateful to the Special Research Fund of Ghent University (BOF-UGent) and the FWO for funding. M.-F.R. thanks the FWO for financial support (G.0065.13N). The authors also thank the Interuniversity Attraction Poles ProgramBelgian State-Belgian Science Policy for financial support.

\section{References}

[1] Luxenhofer R, Han Y, Schulz A, Tong J, He Z, Kabanov AV, et al. Poly(2-oxazoline)s as Polymer Therapeutics. Macromol Rapid Commun. 2012;33(19):1613-1631.

[2] Sedlacek O, Monnery BD, Filippov SK, Hoogenboom R, Hruby M. Poly(2-Oxazoline)s - Are They More Advantageous for Biomedical Applications Than Other Polymers? Macromol Rapid Commun. 2012;33(19):1648-1662.

[3] Weber C, Hoogenboom R, Schubert US. Temperature responsive bio-compatible polymers based on poly(ethylene oxide) and poly(2-oxazoline)s. Prog Polym Sci. 2012;37(5):686-714.

[4] Guillerm B, Monge S, Lapinte V, Robin J-J. How to Modulate the Chemical Structure of Polyoxazolines by Appropriate Functionalization. Macromol Rapid Commun. 2012;33(19):16001612.

[5] Saegusa T, Kobayashi S, Yamada A. Kinetics and mechanism of the isomerization polymerization of 2-methyl-2-oxazoline by benzyl chloride and bromide initiators. Effect of halogen counteranions. Makromol Chem. 1976;177(8):2271-2283.

[6] Saegusa T, Ikeda H. Isomerization Polymerization of 2-Oxazoline. VI. Kinetic Study on the Polymerization of 2-Methyl-2-oxazoline Initiated by Methyl Iodide. Macromolecules. 1973;6(6):808-811.

[7] Saegusa T, Ikeda H, Fujii H. Isomerization Polymerization of 2-Oxazoline. IV. Kinetic Study of 2-Methyl-2-oxazoline Polymerization. Macromolecules. 1972;5(4):359-362.

[8] Müller P, Wörner C, Mülhaupt R. 1,3-Oxazoline intermediates in reactive processing applications, 2.multiphase polymer blends via in-situ cationic melt phase polymerization of 2phenyl-1,3-oxazoline. Macromol Chem Phys. 1995;196(6):1929-1936.

[9] Hoogenboom R, Fijten MWM, Schubert US. Parallel kinetic investigation of 2-oxazoline polymerizations with different initiators as basis for designed copolymer synthesis. J Polym Sci, Part A: Polym Chem. 2004;42(8):1830-1840.

[10] Kobayashi S, Iijima S, Igarashi T, Saegusa T. Synthesis of a nonionic polymer surfactant from cyclic imino ethers by the initiator method. Macromolecules. 1987;20(8):1729-1734.

[11] Loontjens T, Rique-Lurbet L. Synthesis of $\alpha$ alkyl cotrimethoxysilane polyoxazolines and their application as coatings on glass fibres. Des Monomers Polym. 1999;2(3):217-229. 
[12] Guinot P, Bryant L, Chow TY, Saegusa T. Random and block 2-alkyl-2-oxazolines telechelic macromonomers. Macromol Chem Phys. 1996;197(1):1-17.

[13] Theogarajan L, Desai S, Baldo M, Scholz C. Versatile synthesis of self-assembling ABA triblock copolymers with polymethyloxazoline A-blocks and a polysiloxane B-block decorated with supramolecular receptors. Polym Int. 2008;57(4):660-667.

[14] Nardin C, Hirt T, Leukel J, Meier W. Polymerized ABA Triblock Copolymer Vesicles. Langmuir. 1999;16(3):1035-1041.

[15] Fijten MWM, Haensch C, van Lankvelt BM, Hoogenboom R, Schubert US. Clickable Poly(2-Oxazoline)s as Versatile Building Blocks. Macromol Chem Phys. 2008;209(18):18871895.

[16] Hoogenboom R, Fijten MWM, Kickelbick G, Schubert US. Synthesis and crystal structures of multifunctional tosylates as basis for star-shaped poly(2-ethyl-2-oxazoline)s. Beilstein J Org Chem. 2010;6:773-783.

[17] Luxenhofer R, Bezen M, Jordan R. Kinetic Investigations on the Polymerization of 2Oxazolines Using Pluritriflate Initators. Macromol Rapid Commun. 2008;29(18):1509-1513.

[18] Kowalczuk A, Kronek J, Bosowska K, Trzebicka B, Dworak A. Star poly(2-ethyl-2oxazoline)s - synthesis and thermosensitivity. Polym Int. 2011;60(7):1001-1009.

[19] Fijten MWM, Hoogenboom R, Schubert US. Initiator effect on the cationic ring-opening copolymerization of 2-ethyl-2-oxazoline and 2-phenyl-2-oxazoline. J Polym Sci, Part A: Polym Chem. 2008;46(14):4804-4816.

[20] Kuhn R, Ruelius HW. Über die Umsetzung von Diazomethan mit Zwitter-Ionen und anorganischen Salzen. Chem Ber. 1950;83(5):420-431.

[21] Pasto DJ, Cottard F, Jumelle L. Photooxidation of Alkyl 4-Nitrophenyl Sulfides and Sulfoxides. Observation of Oxidative C-S Bond Cleavage and Rearrangement Reactions. J Am Chem Soc. 1994;116(20):8978-8984.

[22] Jacobson BM, Lewis ES. Group transfers. 2. Solvolysis of isopropyl arenesulfonates in sulfolane. J Org Chem. 1988;53(2):446-447.

[23] Wiesbrock F, Hoogenboom R, Leenen MAM, Meier MAR, Schubert US. Investigation of the Living Cationic Ring-Opening Polymerization of 2-Methyl-, 2-Ethyl-, 2-Nonyl-, and 2Phenyl-2-oxazoline in a Single-Mode Microwave Reactor†. Macromolecules. 2005;38(12):50255034.

[24] Wiesbrock F, Hoogenboom R, Abeln CH, Schubert US. Single-Mode Microwave Ovens as New Reaction Devices: Accelerating the Living Polymerization of 2-Ethyl-2-Oxazoline. Macromol Rapid Commun. 2004;25(22):1895-1899.

[25] Levenberg K. A method for the solution of certain non-linear problems in least squares. Quart Appl Math. 1944;2(2):164-168.

[26] Marquardt DW. An Algorithm for Least-Squares Estimation of Nonlinear Parameters. SIAM Soc Ind Appl Math J Sci. 1963;11(2):431-441.

[27] Toloza Porras C, D'hooge DR, Van Steenberge PHM, Reyniers M-F, Marin GB. ICAR ATRP for Estimation of Intrinsic Macro-Activation/Deactivation Arrhenius Parameters under Polymerization Conditions. Ind Eng Chem Res. 2014;53(23):9674-9685.

[28] Stang PJ, Hanack M, Subramanian LR. Perfluoroalkanesulfonic Esters: Methods of Preparation and Applications in Organic Chemistry. Synthesis. 1982;1982(02):85-126.

[29] Beard CD, Baum K, Grakauskas V. Synthesis of some novel trifluoromethanesulfonates and their reactions with alcohols. J Org Chem. 1973;38(21):3673-3677.

[30] Kobayashi S, Tokuzawa T, Saegusa T. Cationic ring-opening isomerization polymerization of 2-[p-(substituted)phenyl]-2-oxazolines. Effects of the substituent on the reactivities. Macromolecules. 1982;15(3):707-710. 


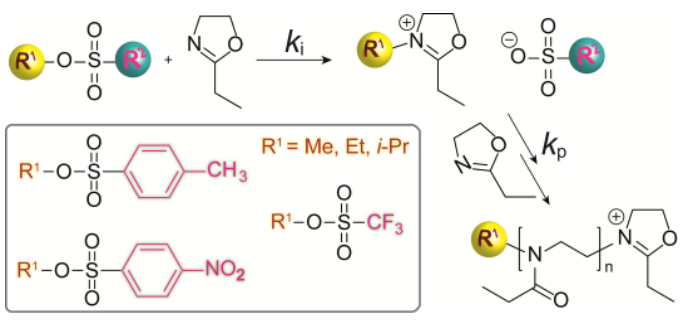

